\title{
Making Sense of Environmental Complexity in a Reform Context: The Case of Megaproject Alpha
}

\section{Marcel Veenswijk}

Department of Organizational Sciences, VU University Amsterdam, Amsterdam, The Netherlands.

Email: m.veenswijk@vu.nl

Received April 19 ${ }^{\text {th }}, 2012$; revised June $4^{\text {th }}, 2012$; accepted June $19^{\text {th }}, 2012$

\begin{abstract}
In this paper, new concepts on environmental complexity and sense making are developed and explored and analysed. The article based on a case study regarding a public-private collaboration in a Dutch infrastructural mega project. It is argued that the ability to influence the direction of the change process of the mega project "Alpha" depends on the way actors are able to influence the so aleed "cultural interfaces" into the power arena by means of a specific group of organizational stakeholders. After a short theoretical introduction, we describe the case in terms of two dominant cultural stages and their specific interface dynamics. The paper concludes with a general reflection on the central concepts.
\end{abstract}

Keywords: Project Management; Mega Projects; Narratives of Change; Intervention; Public-Private Collaboration; Change Dynamics

\section{Introduction}

Although the societal impact of large scale construction projects ("Mega projects") is enormous, academic interest on this subject has been modest. The discussion seems to be limited to the rational organization and (political) control in terms of policy programs, contracting, perceived outcomes, and especially risk and economic failures [1].

Mega projects are considered to be as much the object and outcome of social interactions as any other form of organizing within a multiple context of socially interdependent networks. The institutional connotation related to "policy formulation versus implementation", "design versus construct" or even "BOOT" (Build Own-OperateTransfer) are ways of bracketing normative (first order) reality definitions of these relationships. Mega project can be discerned from other enterprises in terms of content (including the physical artefacts that result from the projects), temporality (the assumption that the project reality is limited in linear timescales and spaces), contextual "patching" (the idea that ambiguity is excluded via politically) legitimized contractual modes, and social variation (amount of social interactions related to the projects mission and goals) [2].

In the late 1980's of the last century, many European countries worked on an European network of high speed railways. The ministers in the European Commission of Transport gave in 1990 their approval to the development of an European high speed railway network. The European infrastructural network was intended to improve the economical situation in the European Community and to form an environmental friendly alternative for air and car travel in Europe. The Netherlands, as part of the European Community, developed two distinct high speed railways; one to the south and one to the east. As with other European countries, a part of the financial support came from the European Community [3].

The first plan for developing the high speed railway south and east was presented to the Dutch government already in 1991. Because of the social and environmental impact of the project on the dense populated Netherlands, and because of the financial consequences only the high speed railway to the south was approved by the government. A project-organization (called Alpha team), rewrote the plans into a huge memorandum of more than 23 reports. An important condition in the construction of the railway was the need of partly private finances. Furthermore, the infrastructure should be exploited profitably. In 1996 the Dutch parliament agrees upon the construction of project Alpha to realize a safe and comfortable train passage from Amsterdam to Belgium with a speed of 300 kilometers a hour.

During the last decade, infrastructure became one of the main issues on the Dutch political agenda, Project Alpha attracted a lot of (international) attention, not only for their societal implications, but particularly because they were characterized by major deviations in terms of 
overspending, incorrect timeframes/planning and corrupttion, which resulted in intensive parlementairy inquiries and a redesign of control models and steering design. Originally, the project was designed as (experimental) public-private constellations in which public and private actors participated and had a joint responsibly for construct and design, as well as for exploitation. Although most of the designing was actually the result of public-private cooperation, and the hybrid organizational construction was reflected in the way the project organizations were empowered $(70 \%$ of the employees were hired on a temporal basis, 30\% were public employees), exploitation remained a matter of the state. This also counts for the (public sector) hierarchical-machine likeformal construction which was chosen in order to build the projects. The top managers of the project organization were all public employees. The CEO, (called Hoofdingenieur directeur), reported (via the secretary-general of the ministry) to the Minister of Transport [4].

This paper focuses on the ways actors within the Alpha project deals with environmental complexity in a shifting reform context. Alpha project is one of the largest infrastructural project in the history of the Netherlands. Many technological complex problems had to be solved to dig a seven kilometre long tunnel in instable clay, to build bridges over wide rivers, to stabilize the railway in swampy grounds and to reduce environmental impact in dense populated areas. Furthermore, thousands of civilians living next to the high speed railway are involved as well as 19 local governments, three counties and twelve offices for water management. The complexity for realization of the mega-infrastructural project was increased by the many construction and engineering companies, governmental departments, the Dutch Railways and many other organizations.

This project is relevant because it contains a specific form of complexity which cristallizes in an organizational arrangement, based on the idea of "loose coupling" via multi-lateral contract-forms. The case describes the way the project was internally organized, the art of the contracting relations between the various actors and the surveillance structure around these contracting/control modes.

After introduction of the theoretical nese, the case is introduced and presentated in four basic episodes. The analysis of the cases is concluded with some conclusive remarks as well as a reflection on basic theoretical concepts.

\section{Theoretical Backgrounds}

Ethnographic studies on organisational configurations underline the notion that (concepts of external) project environments are subject to processes of social construc- tion [5]. In order to cope with contextual complexity and ambiguity, project actors construct a more or less stable working environment for themselves. The subjective state of "world-openness" changes along with the dynamics of the project into an objectified situation of world-closedness, which strongly influences and steers actors' behaviour within that stabilised environment.

"Organisational environment" is one of the broadest concepts in organisational studies, as it can be extended to include almost every aspect of physical and textual context. Organisational scientists use the term "organisational environment" to refer to nations, politics, economics, technology, history, physical settings, demographics, religions, regions, occupations, and industries. The distinction between organisations and their environment makes it possible for organisational scientists to consider organisations as separate entities. Yet, the two are not easy to separate. By drawing a clear boundary between organisations and their environments, new questions about the permeability of these boundaries arise. Organisational members simultaneously perform activities inside and outside of organisations. For that reason, Pfeffer and Salancik defined the control of organisations over the activities of employees as one of the central boundaries of an organisation [6]. Beyond these boundaries, the influence of an organisational environment on the activeties of employees is more dominant than internal organisational control. Starbuck defined multiple boundaries by one's distance from an organisation's centre. The first boundary includes both organisational members and people who are conventionally regarded as members of other organisations but who are involved in the organisation's activities. The second boundary implies that all those without are not involved in the organisation's activities [7].

Organisations and environments are interrelated since organisations are dependent on their environment, and environments create uncertainties for organisations. This interdependence receives primary attention in the open systems perspective. Any boundary between an organisation and its environment is partially arbitrary; organisations are perceived as open systems with permeable boundaries. Scott sees organisations as "open systems", in which an organisation can be characterized as a coalition of shifting interest groups which develop goals through negotiation. The structure of the coalition, its activities and its outcomes are strongly influenced by environmental factors [8].

To solve the "problem" of permeable boundaries between organisations and their environments, organisational anthropologist Chanlat developed a framework to study organisations and their environments by focusing on human behaviour while at the same time exploring all the relationships within the environment which run 
through organisational life at different levels. Chanlat used a holistic analysis of organisational environments to understand the behaviour of individuals in organisations. He distinguishes five closely linked levels of organisational reality. The first level is the individual level, in which Chanlat sees human reality as a subtle interaction of the biological, the psychic and the social. At this level, individuals construct and deconstruct their own reality and cope with conflicts, tensions, uncertainties and ambiguities. At the second level, the interactional level, the identity of an individual is formed in interactions with others. These interactions, formal and informal, can take place between two different individuals or between two different groups. The third level, the organisational level, focuses on organisational cultures. The fourth level, the society level, concerns national cultures. These national cultures have evolved due to geography, history, political and economic forces, language and religion. The fifth level, the global level, deals with such transnational ideologies as religion, globalization and liberalization [9]. Each level is analytically independent and contains elements which are linked to each other in relatively stable relationships. There is no hierarchical relationship between the different levels; the levels are contingent in nature and the relationships can move in any direction. Actors more or less "externalize" the different levels, according to their specific perspective and project configuration.

According to Berger \& Luckman, externalization is a basic condition for survival in a social context. As a result of continual externalization, some aspects of the social world are objectified, providing them with a status which is unrelated to the individual who has externalised them. Objectification concerns the process in which patterns of behaviour of specific aspects of human activity become "facts" external to actors [10].

Weick stated that cultural development in organisational contexts can only be understood by means of processes which develop within organisational configurations. In his opinion, these processes can be divided into three sequential phases [11]. The first phase he distinguished is enactment. Actors create a context or environment for themselves, from which they constantly select and enact a number of elements which they regard to be relevant. According to Weick, actors continuously ascribe new meaning to their reality, rather, to their context during interaction.

As project members are constantly communicating with each other and adjusting their behaviour so that it is in line with that of others, they are continually actively interfering with their own environment. In other words: in their daily interactions they create a significant part of what they experience as their central meaning patterns. Of the many contextual facts, some aspects are called "relevant", while others are dismissed as "irrelevant". This selective bracketing of facts results in such a reduction of complexity that it becomes acceptable to maintain it as a useful reality. Through this process of enactment, actors generate their own subjective view of reality throughout time. After the first phase of enactment, the next phase, selection, can begin. In this phase, the parts of "reality" that can be used in a certain situation are selected using a complex of criteria. After all, the project actors have isolated the facts that have been placed between brackets during the first phase, but they have not yet been interpreted and rid of any ambiguity. In the phase of selection, the rough data from the environment is interpreted using cognitive maps. These are causal structures that provide information over the meaning that facts have in regard to each other.

In the final phase, those of retention, a further reducetion of the complexity takes place. Not only is the taking in of new information characteristic for this phase; information that is already stored in one's memory is also tested. Through this, a number of "gestalts" arise, with which new situations can be "recognised" quickly and can be reacted upon using the logic of the gestalts. Should new information no longer "fit" with the stored information (or with the gestalt) then, in time, a modification in the cognitive structure will take place. For Weick, project development is no more than a group of social processes, in which individual actions of two or more actors are related within an environmental context. By that he means that the action logic of various interacting actors is related. According to Weick, that link can be observed when the actions of actors that are busy talking to each other are analysed: one person's behaviour turns out to be "correlated" to the other person's behaviour and vice versa. The main line is that the process of cultural development is an action circle in which the phases of enactment, selection and retention continually alternate [12].

The elements that are regarded as relevant are placed "between brackets" in order to reach an acceptable reducetion of ambiguity. Actors interpret the elements that have been placed between brackets using their own webs of significance. These webs of significance develop during processes of interaction between actors. After the elements of the context have been interpreted, they are stored in the actor's memory in the retention phase and set up against information that has been internalised by the actor in an earlier phase. In this phase, actors' activities develop into routines. Events and problems that the actor faces are 'recognised' from an existing frame of reference and solutions are created from the patterns developed in previous phases. In time, the elements, approach to problems and attributes with which one is confronted, become reifications: They reach the status of 
"fact" or "objectivity". It is taken for granted that these objectifications have no independent reason for existence outside of actors. However it is also assumed that these "facts", which are recognised as such by certain actors, can be taken over by other actors in processes of interaction and as such be internalised by others.

In traditions and rituals, certain ideas and action patterns of project actors are passed on. Changes in webs of significance arise when certain elements are enacted through processes of interaction and therefore no longer fall within existing cognitive maps [13]. Actors find themselves confronted with problems and challenges they did not have to deal with in the past and, through processes of interaction, they create a new "reality" that can be used to solve them [14]. For instance, the rise of information technology has had major cultural conesquences for many project organisations. More than in the past, the frames of reference that have developed in light of the new technological developments are about technical superiority and the belief in the fact that technically "loaded" projects are able to provide a "rational solution" for problems that seem impossible to solve. We see this in the case of ALPHA, which illustrates the organisational reflection in terms of technical as well as social and moral constructed environmental definitions.

\section{Research Methods}

The ALPHA case reconstruction is a result of intensive study, which was executed by a team of a senior researcher and two research assistants. The research in the ALPHA case was "sliced" into a number of phases, in which the attention shifted from element to element of the culture being studied. The most important motivation for a phased method was that it is the only way for a researcher to create a well-organised and controllable research agenda with room for interim reflection and correction of possible "blind spots". The research was split up into four main phases: 1) General orientation on the project environment within which the organisation operates; 2) Analysis of important documents from the organisation and the context of the unit that was to be studied; 3) Focussed interviews with employees, exemployees and relevant key figures from the environment; 4) Search for confirmation of the conceived re search data and interpretations. Naturally, each phase started with an introduction, in which agreements were reached on the research and a short presentation of the method was given. During a period of six months (semi) open individual interviews were held with 20 stake-holders within the project and 20 actors in the context of the Project organisation, especially clients (10), representatives of pressure groups (5) and general public (5). Further, key meetings were observed and important documents were analysed.

\section{Case Description}

From the start, European stakeholders described the ALPHA project in terms of its innovative capacity "unique” character [15]. Early policy papers report about the innovative cocepts and creative management philospohy.

The project team that created the project infrastructure was defined as "professional entrepreneurs": A highly trained group of expers with a large mandatory budget. The project was originally designed as an (experimental) public-private constellation in which public and private actors participated and had a joint responsibly for construct and design, as well as for exploitation.

The organization consisted of a so called public-private (BOOT) arrangement (seventy percent of the employees were hired on a temporal basis, thirty percent were public employees), exploitation remained a matter of the state. This also counts for the (public sector) hierarchical-machine like-formal construction, which was chosen in order to build the project. The top managers of the ALPHA organisation were all public employees. The CEO (the engineer who is the responsible for the technical part of the entire project) reported via the secretary-general of the ministry to the Minister of Transport. The project can be described in two (more or less) successive episodes, with a timeframe of ten years.

Phase 1: Controlling environmental complexity through separation (1996-2001)

The reason for using a complete set of new techniques and readjustments had to do with the highly unstable physical circumstances. For example, in order to spare the valuable scenic landscape it was decede to make a large tunnel. For this, a (unique) construction with a diameter of almost 15 metres should be one of the largest bored tunnel in the world. Because of its technical superiority and ecologically sound design, this tunnel became the symbol of the ALPHA "high-tech" quality.

The project organization deceide to divide the project in five project agencies, connecting the different geographical entities. The interconnection was realized via various ranges of contracts, between the principal and the agencies on the on hand and between private architects, or constructors, and the agencies on the other hand. In total, there were more than 900 (sub) contracts in operation.

Monitoring of the contracts took place on a quarterly basis, and surveillance was arranged via a complicated set of ICT-systems. Athough initially, the management of ALPHA project centred in Capital City (Ministry of Transpor) after one year the leading project team moved to a separate location outside Capital City. As a result of 
large scale reorganizations in the Ministry and new regulation acts, the project team was forced to internalize new "subsets of behaviour" regarding the management of the project. The European guidelines (e.g. Technical Specifications for Interoperability) also had to be incorporated therein. A concessions act was going to be passed which was to regulate the relationship between a Transport Operating Company (TOC) and the State. The relationship between the State and the Infra manager was going to be regulated by means of a concession [16].

The impact of the changes concerned more than just the project organization. The original idea to divide all the work into some forty traditional contracts (including the idea that the railway would be responsible for the "commercial customer part") was rigorously altered. The outcome of the severe discussions resulted in a thirty year covering Design, Build, Finance and Maintain core contract, which included a set of five connected Design \& Construct sub-contracts [17].

Since there was only limited experience of driving at high speed, a railway construction without (the usual) ballast was created; besides the planned (one of the largest) underground Tunnel (in terms of its diameter in mellow soil) this was one of the major innovations in the project.

As part of the management "ideology", the credo "decentral unless" coverd the basic responsibilities between the Ministry on the one hand and the ALPHA orgnaization on the other hand. The contractors were held responsible for the planning and budgetary issues. Interventions from the ministry were only accepted in specific, crisis like situations. The logic behind this was that managers "on spot" were probably better informed than their colleagues in Capital City.

In 2002, a new conflict arose around the quarterly reports. The reports were available in a limited online environment, but only a small group of team members had access to the data and were able to interpret deviations.

While the "frontstage" reality of the project, more and more became dominated with technical imperatives and technical/rational models of report, day to day reality showed a different picture. Conflicts about the work were only partly visible in the reports and were kept "backstage" within the subgroups [18].

Conflict issues, such as lack of trust on accuracy of data between different parties, cultural tensions between the groups, inadequate communication and frequency of report lead to a growing tension between the principal actors (Ministry) and the project team.

The conflicts resulted in a set of interventions, which were indicated by the Ministry. Not only was a new top executive appointed and made responsible for the entire project organization. Also the organizational vision was transformed into a "central unless” adagium, backed with series of dialogue sessions, round tables and job rotations in which the different contract teams were more or less forced to operate. In order to deal with the "information problems", a specific set of new reporting procedures were implemented and a major reduction and clustering of contracts was decided upon.

\section{Stage 2: Institutional transplantation and consoli-} dation (2003-2010)

Six months after the implementation of the intervenetions, a new chapter in the project started. "System-Integration" became the new focus and basically concerned the connections between the basic main ports as well as ways to deal with risk items concerning the interconnections.

The team claimed that additional risk reservations and as a result of this: New financial claims, which-againcaused media commotion and a political quest to restructure the organization of ALPHA. A tripartite Board of Directors (role model for all the CCE directorates) was installed in which the connection with the Infra manager and the responsibility for the control of the project was strongly emphasized. In addition, the main department of Transportation, Safety and System-integration was split up, as was the main department that managed the contract with Trail [19].

Besides the Ministry and claims of political representtatives, the ALPHA project team members were confronted with additional problems that were hardly predictable. For instance, the problems that arose in 2003 with regard to the height of platforms at the stations situated along the ALPHA-railway. In order to standardize the high-speed rail system a series of European directives by the European Transport Committee, e.g. Directive 2001/16 which is part of the EU Safety Rules were introduced. Alpha was forced to standardize many objects in their project, such as the height of platforms. Adaption to these new "complexities" caused new uncertainties and tensions in the ALPHA organisation. During the implementation of the directive, most of the technical blueprints of the stages had already been completed and the team realized that redesigning the stages would be very expensive. Eventually, new blue prints were constructed, with a new delay of several months.

Implementation of the Railway Act in 2006, resulted in a new focus shift. The project as such more and more became the shadow to the transportation component. And this resulted once again in tensions. In line with this, control-oriented issues about the transportation component came up, such as: "we wish to make agreements with the ALPHA", or "the ALPHA should do X", or "when will the ALPHA do Y" etcetera. Questions which did not square with the nature of the agreement with the ALPHA, a rather functional and distant (public) agreement, respectively did not square with the formal position 
of the management of the ALPHA. Often questions arose around specific responsibilities of project managers versus responsibilities the Ministry of Transport or the Infra manager. These comments were not taken well, and also the interpretation of there role as a team-behind the scenes, informal, influential, helpful, statutorily pure, helping everyone to assume their assigned roles, and hold them to it-came under pressure as a result.

Although the reflection on the mission of the project remained a central issue to the Alpha team until the end of the project, the "Integral Transport System" and "TurnKey Delivery", appeared to be the ultimate political messages for the entire management of the ALPHA. These issues not only became a mantra for political representatives, but at the same time created an efficient wall to hide behind when "difficult questions" came up, regarding next steps and new projects.

\section{Analysis and Conclusions}

In the case of the Alpha project, the cost factor became the major struggle for management as well as for political representatives. As we have seen, the original decentralization oriented strategy pushed towards a large variety of types and amounts of internal contracts. Although the one sided focus on contracting was seen as a crucial vehicle in the battle against cost overrun, this strategy was insufficient. The (relatively) separated contracts were related to specific artefacts (like bridges, tunnels, platforms, etc.) and cost overrun on these sub-contracts did not act as trigger for redesign on the other projectartifacts. On the contrary, local actors often considered the completion of an artefact like a tunnel (despite the cost factor) as an act of strong management and decisiveness, a result of courage to "stand up" against central bureaucrats that should be followed by the other project agency-managers. In the last phase of the project, contract standardization was heavily increased by the (new) project director of the HSA-organization. Project controllers were empowered to intervene "if necessary". The quarterly reports were based on the complicated reporting procedures and ICT-systems. The reports about the various sub-projects more and more acted as internal bench and as vehicles for administrative and organizational improvements ("standard issues" for instance were - in terms of time and cost - technical development, risk calculation, human capacity, environmental developments and communication) for the central management. At the same time, contract-reality became detached from the "day to day" organizational practices and the problems that were experiences in terms of internal cooperation, communication, team spirit and trust in the quality of the project outcome. Internal organizational audits (pinpointed to major organizational-cultural problems and related risks in terms of communication gaps, uninspiring management concepts/styles and internal distrust.

Although the (quarterly and annual) reports were available via the intranet, only a small group of professionals were able to read and interpret the report results. Project-agency managers "translated" the results in terms of their own organizational reality and strategically presented the information for own purposes [20]. In ALPHA, the complexity reduction approach leads to multiple organisational weaknesses. Entrepreneurship, innovation and courage, marked as critical issues by almost all key ALPHA players in the frontstage, become completely subordinate as a result of quotidian concerns and costrelated arguments. In the actual practice of the project team members, innovation appears to boil down to a simple struggle for survival by means of the creative translation of common agreements, pushing and pulling around points of contention, establishing internal coalitions and looking after one's own interests.

\section{REFERENCES}

[1] B. Flyvbjerg, M. K. S. Holm and S. L. Buhl, "Underestimating Costs in Public Works Projects. Error or Lie?” American Planning Association Journal, Vol. 68, No. 3, 2002, pp. 279-295. doi:10.1080/01944360208976273

[2] A. Van Marrewijk and M. Veenswijk, "The Culture of Project Management, Understanding Daily Life in Complex Megaprojects,” Prentice Hall, Harlow, 2006.

[3] M. Veenswijk, "Cultural Change in the Public Sector: Innovating the Frontstage and Backstage,” In: M. Veenswijk, Ed., Organizing Innovation, New Approaches to Cultural Change and Intervention in Public Sector Organizations, IOS Press, Amsterdam, 2005, pp. 3-14.

[4] M. Veenswijk, "Surviving the Innovation Paradox: The Case of Megaproject X,” The Innovation Journal, Vol. 11, No. 2, 2006, pp. 1-14.

[5] K. E. Weick, "Sensmaking in Organisations," Sage, London, 1995.

[6] J. Pfeffer and G. R. Salancik, "The External Control of Organisations: A Resource Dependence Perspective,” Harper \& Row Publishers, New York, 1978.

[7] W. H. Starbuck, "Organisations and Their Environments," In: M. D. Dunette, Ed., Handbook of Industrial and Organisational Psychology, Rand McNally Publishers, Chicago, 1976, pp. 1069-1124.

[8] W. R. Scott, "Organisations, Rational Natural and Open Systems,” Prentice Hall, London, 1981.

[9] J. F. Chanlat, "Francophone Organizational Analysis," Organizational Studies, Vol. 15, 1994, pp. 47-79. doi:10.1177/017084069401500103

[10] P. L. Berger and T. Luckmann, "The Social Construction of Reality,” Garden City, New York, 1976.

[11] K. E. Weick, "Sensmaking in Organisations," Sage, London, 1995. 
[12] M. Veenswijk, “Organizing Innovation, New Approaches to Cultural Change and Intervention in Public Sector Organizations,” IOS Press, Amsterdam, 2005.

[13] K. P. McLaughlin, S. R. Clegg, M. Marosszeky and T. Rura-Polley, "Constructing the Olympic Dream: A Future Perfect Strategy of Project Management," Organisation Science, Vol. 14, No. 5, 2003, pp. 574-590.

[14] M. B. Veenswijk and C. Chisalita, "The Importance of Power and Ideology in Communities of Practice: The Case of a De-Marginalized User Interface Design Team in a Failing Multi-National Design Company,” International Journal of Technology and People, Vol. 20, No. 1, 2007, pp. 483504.

[15] Note: Parts of These Episodes Are Alsoc Described in Veenswijk, 2006.

[16] A. G. Dorée, "Collusion in the Dutch Construction Industry: An Industrial Organization Perspective,” Building Research \& Information, Vol. 32, No. 2, 2004, pp. 146156. doi:10.1080/0961321032000172382
[17] G. Van Den Heuvel, "The Parliamentary Enquiry on Fraud in the Dutch Construction Industry Collusion as Concept Between Corruption and State-Corporate Crime," Crime, Law \& Social Change, Vol. 44, No. 2, 2005, pp. 133-152. doi:10.1007/s10611-006-9009-5

[18] M. Berendsen and M. Veenswijk, "Constructing New Working Practices through Project Narratives," International Journal of Project Organization an Management, Vol. 1, No. 1, 2008, pp. 65-85. doi:10.1504/IJPOM.2008.020029

[19] H. Sminia, "Institutional Continuity and the Dutch Construction Industry Fiddle,” Organization Studies, Vol. 32, No. 11, 2011, pp. 1559-1585. doi:10.1177/0170840611425724

[20] M. B. Veenswijk, A. H. van Marrewijk and F. K. Boersma, "Developing New Knowledge in Collaborative Relationships in Megaproject Alliances: Organizing Reflection in the Dutch Construction Sector," International Journal of Knowledge Management Studies, Vol. 4, No. 2, 2010, pp. 216-232.

doi:10.1504/IJKMS.2010.030793 